\title{
Sputum Bacteriology and Antibiotic Sensitivity Pattern of Patients Having Acute Exacerbation of COPD in India - A Preliminary Study
}

\section{Anand K. Patel ${ }^{1 *}$, Atul S. Luhadia ${ }^{2}$ and Shanti Kumar Luhadia ${ }^{2}$}

${ }^{1}$ G. M. E. R. S. Medical College \& General Hospital, Gotri, Vadodara, Gujarat, India

${ }^{2}$ Geetanjali Medical College \& Hospital, Udaipur, Rajasthan, India

\begin{abstract}
Background: Chronic Obstructive Pulmonary Disease (COPD) is a common disease and equally affecting rural population. Majority of COPD exacerbations are infective and facilities of bacterial culture are not available at peripheral health institutions. Acute exacerbations can contribute to irreversible progression of disease.

Objective: To find out the bacteria predominantly causing the AECOPD in our region, its relation with severity of the diseases and antibiotic most effective against these organisms.

Material and Methods: Previously diagnosed patients presented with acute exacerbation were investigated for sputum characteristics, culture and drug sensitivity.

Results: Culture was positive in 41 (82\%) patients. Streptococcus pneumoniae (32\%) was the most common pathogen isolated followed by Streptococcus pyogens (16\%) and Pseudomonas (12\%). Piperacillin+tazobactum was the most effective antibiotic against all organisms. Quinolones were less effective.

Discussion: Sputum culture was positive in $82 \%$ of patients with AECOPD which was higher as compare to other studies. On the contrary positive growth in $97 \%$ of samples has also been found. This difference may be because of the fact that culture positivity depends on nature of sputum, time of collection sputum and previous antibiotic use.

Conclusion: Streptococcus pneumoniae is still the most common pathogen in patients with AECOPD of this area. Piperacillin+tazobactum should be the first choice empirical antibiotic. Quinolones should be used cautiously in area where prevalence of tuberculosis is high. However more studies with larger population required which also includes bronchoscopic sampling along with sputum.
\end{abstract}

Keywords: Sputum; Bacteriology; Antibiogram; Acute exacerbation; Chronic obstructive pulmonary disease

\section{Introduction}

Chronic Obstructive Pulmonary Disease (COPD) is characterized by persistent airflow limitation that is usually progressive and associated with an enhanced chronic inflammatory response in the airways and the lung to noxious particles or gases [1]. COPD is the fourth leading cause of death in the world and will become the third leading cause of death worldwide by 2020 [1]. Four to ten percent adult male population of India and 3.5 to $6.5 \%$ population in Asia pacific countries suffer from this disease [2].

An exacerbation of COPD is an acute event characterized by a worsening of the patient's respiratory symptoms that is beyond normal day-to-day variations and leads to a change in medication [1]. Acute exacerbations forms the major component of economical burden of COPD [3]. AECOPD also leads to indirect costs because of days lost from work [4]. It is the important factor of mortality in COPD patients.1 AECOPD cause great impact on individual health and health care system in India also [2]. Acute exacerbations can contribute to irreversible progression of disease [5]. Therefore timely institution of correct management is imperative for better prognosis of disease. Bacterial infections are the most common cause of AECOPD [1]. It is estimated that bacterial infections are responsible for more than $40 \%$ of all exacerbations in India [6]. It has been found that use of antibiotics as well as type of antibiotics used to treat AECOPD has an impact on the failure rate [7]. Proper selection of antibiotic selection needs culture studies but it is time consuming and not available in majority of peripheral health institutions. Bacterial flora of AECOPD is changing from usual pathogen [8]. The choice of the antibiotic should be based on the local bacterial resistance pattern [1]. Therefore the knowledge of bacterial flora of patients of AECOPD of that geographical area is required [9].

Facilities of bacterial culture are not available at majority of peripheral health institutions. There is no such study has been carried out in this part of country (Gujarat) and very limited data is available from India. Knowledge of local bacterial etiology and antibiotic sensitivity patterns of AECOPD facilitates early introduction of proper empirical antibiotics which can reduce the morbidity, mortality and improve prognosis particularly at peripheral level where facility for culture studies are not available. Current data on bacteriology related to AECOPD are mainly derived from the western countries. There are very limited data available in this aspect from Asia Pacific region.

So, we conducted this study to know the bacteria predominantly causing the AECOPD in our region and the antibiotic sensitivity pattern of these organism so that we can design a proper antibiotic regimen which will have a beneficial effect on the morbidity and mortality of the disease.

${ }^{*}$ Corresponding author: Dr. Anand K. Patel, MD, FCCP, G. M. E. R. S. Medical College \& General Hospital, A/16 Krishnadeep Society, B/h Saurabh Park, Near Samta, Subhanpura, Vadodara-390023, Gujarat, India, Tel: +919879771079;E-mail: dranandkpatel@gmail.com

Received December 15, 2014; Accepted January 22, 2015; Published January 26, 2015

Citation: Patel AK, Luhadia AS, Luhadia SK (2015) Sputum Bacteriology and Antibiotic Sensitivity Pattern of Patients Having Acute Exacerbation of COPD in India - A Preliminary Study. J Pulm Respir Med 5: 238. doi: 10.4172/2161-105X.1000238

Copyright: (C) 2015 Patel AK, et al. This is an open-access article distributed under the terms of the Creative Commons Attribution License, which permits unrestricted use, distribution, and reproduction in any medium, provided the original author and source are credited. 


\section{Materials and Methods}

The present prospective observational study was carried out at Dhiraj General Hospital, Piparia, Vadodara, Gujarat from March 2011 to June 2012 after taking institutional ethical committee permission with the following inclusion and exclusion criteria.

\section{Inclusion criteria}

Previously diagnosed patients of COPD on the basis of history of exposure to risk factors, clinical history and examination supported by spirometry having acute exacerbation according to the following criteria.

\section{Increased dyspnoea}

Increased sputum volume

Increased sputum purulence cells

Sputum sample contains $<10$ squamous epithelial cells and $>25$ pus

\section{Exclusion criteria}

Patients having bronchiectasis, tuberculosis, pneumonia, malignancy and other evident disease on chest $\mathrm{x}$-ray

Patients previously admitted within 21 days and taken antibiotics

Patients having sputum positive for acid fast bacilli (AFB)

After clinical examination, routine $\mathrm{CBC}$, blood sugar, urine examination, X-ray chest PA view, oxygen saturation by pulse oximetry, were done in all the patients. Their early morning sputum was collected in a sterile transparent container after rinsing the mouth with antiseptic solution. The sputum sample was examined for physical appearance, gram stain, AFB smear, pyogenic culture and drug sensitivity for bacteria.

\section{Results}

Total 50 patients were enrolled in the present study comprised of 41 males and nine females having mean age of 60.18 years. All males were smokers while all females though non-smokers, but exposed to biomass fuel. Sputum culture was positive for microbes in $82 \%$ of the patients. It can be seen from Table 1 that out of positive cultures streptococcus pneumonia (39\%) and streptococcus pyogens (19.5\%) were most common pathogens followed by pseudomonas aeruginosa (14.7\%), klebsiella pneumonia (9.7\%), H. influenza (7.32\%), staphylococcus aureus $(4.88 \%)$ and E. coli (4.88\%).

We had observed that out of all six patients with positive culture for pseudomonas aeruginosa, two (33.33\%) had yellow green while four (66.67\%) had green sputum. Out of remaining 44 patients 29 (65.91\%) had white sputum and 15 (34.09\%) had yellow sputum. All patients with yellow sputum had positive culture for pathogens while out of 29 patients having white sputum $20(68.97 \%)$ patients had positive culture for pathogens. All nine patients in whom no pathogen was grown had white sputum. It can be seen from Table 1 that pseudomonas aeruginosa was more common in patients with $\mathrm{FEV} 1<50 \%$ of the predicted value however no correlation was found between other organism with lung function.

Antibiotic sensitivity pattern to all organisms is shown in Table 2. Sensitivity of piperacilline+tazobactum and ofloxacin was tested in all 41 patients while of ciprofloxacin was tested in almost all (40) patients having positive culture for organism irrespective of gram positive or negative. It was found that piperacilline+tazobactum was the most effective antibiotic being sensitive to majority of organisms (95.12\%).
In only two patients (one had positive culture for streptococcus pneumonia and one had staphylococcus aureus) it was found to be resistant while all gram negative organisms were sensitive. Quinolones were less effective being overall resistant of $39.02 \%$ with ofloxacin and $37.5 \%$ with ciprofloxacin. Levofloxacin was also resistant to $33.33 \%$ of patients having gram negative organisms. Co-amoxyclav was resistant to $34.62 \%$ and amoxycilline was resistant to $46.15 \%$ of the patients having gram positive organisms. Among macrolides, azithromycin was the most effective drug against gram positive organisms having resistance of $26.92 \%$ while erythromycin was the least effective drug having resistance of $69.23 \%$. Linezolid was tested in 17 patients having gram positive organism and found to be resistant in $41.18 \%$. Against gram negative organisms; apart from piperacilline+tazobactum, cefoperazone+sulbactum was also $100 \%$ effective while amikacin was sensitive in $92.86 \%$. For most common organisms (streptococcus pneumonia and streptococcus pyogens), piperacilline+tazobactum was most effective antibiotic in our region having sensitivity of $95.83 \%$.

\section{Discussion}

COPD is leading cause of morbidity and mortality and early introduction of empirical antibiotics, can improve outcome and reduce mortality. 8 Since culture facilities are not readily available and time consuming, it is better to know the pattern of bacterial flora and their sensitivity of a particular geographical area. Sputum culture was positive in $82 \%$ of patients with AECOPD which was higher as compare to other studies $[6,10,11]$ This difference may be because of the fact that culture positivity depends on nature of sputum, time of collection sputum and previous antibiotic use. Madhavi et al. [11] have collected repeat samples if first sample were unsuitable after admission which can decrease yield particularly if empirical antibiotics has been started. Sputum collection timing has not been mentioned by Chawla et al. [6], which can affect yield as early morning sample may increase the yield as compared to randomly collected samples. Study by Ko et al. [10] was retrospective and time of collection of sputum has not been mentioned which can decrease yield. On the contrary other author [12] had found positive growth in 85 (97\%) of the 88 representative samples.

In our study Streptococcus pneumniae (32\%) was still the most common pathogen in AECOPD in this area. This finding is contrary to other studies reported from India by Chawla et al. [6] who had found Pseudomonas aeruginosa while Madhavi et al. [11] had found Klebsiella pneumonia was the most common organism. The difference may be because most of the cases in our study were from rural area. Further, they had included more severe patients in their study. We also found pseudomonas aeruginosa was most common in patients having FEV1 $<50 \%$ of predicted value in our study. Few authors [12-14] have found higher incidence of pseudomonas and enterobacteriacae in patients with more severely compromised lung functions. Groenewegan et al.

\begin{tabular}{|c|c|c|c|c|c|}
\hline \multirow{2}{*}{ Pathogen } & \multicolumn{4}{|c|}{ Severity } & \multirow{2}{*}{ Tota } \\
\hline & Mild & Moderate & Severe & Very Severe & \\
\hline No Organism & 3 & 3 & 1 & 2 & 9 \\
\hline Streptococcus Pneumoniae & 0 & 4 & 8 & 4 & 16 \\
\hline Streptococcus pyogenes & 0 & 2 & 5 & 1 & 8 \\
\hline Staphylococcus aureus & 0 & 2 & 0 & 0 & 2 \\
\hline Pseudomonas aeruginosa & 0 & 1 & 2 & 3 & 6 \\
\hline Klebsiella Pneumoniae & 0 & 2 & 0 & 2 & 4 \\
\hline H.influenzae & 0 & 3 & 0 & 0 & 3 \\
\hline E. coli & 0 & 1 & 0 & 1 & 2 \\
\hline Total & 3 & 18 & 16 & 13 & 50 \\
\hline
\end{tabular}

Table 1: Co-relation between severity of Chronic Obstructive Pulmonary Disease (COPD) and pathogens isolated from sputum. 
Citation: Patel AK, Luhadia AS, Luhadia SK (2015) Sputum Bacteriology and Antibiotic Sensitivity Pattern of Patients Having Acute Exacerbation of COPD in India - A Preliminary Study. J Pulm Respir Med 5: 238. doi:10.4172/2161-105X.1000238

Page 3 of 4

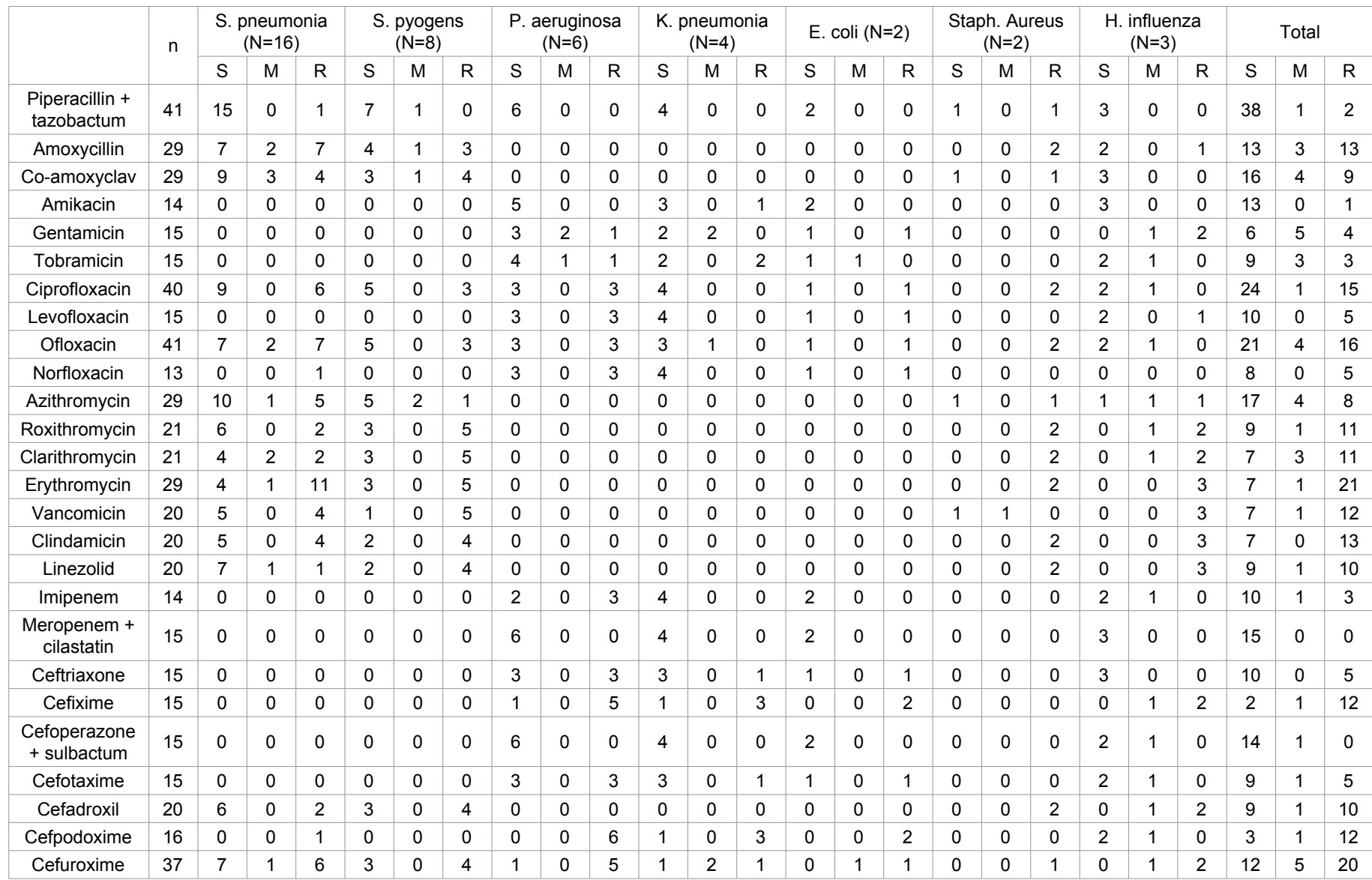

Table 2: Drug sensitivity pattern of various pathogens isolated from sputum ( $n=$ total number of patients tested, $S=$ sensititve, $M=m o d e r a t e l y ~ s e n s i t i v e, ~ R=$ resistant).

[12] had also included more severe patients but found hemophilus influenza (45\%) as most frequent organism followed by streptococcus pneumonia (27\%). However data on relationship between organism and lung function is scarce, it needs more studies with large number of patients.

We found that the piperacilline+tazobactum was the most effective organism in this area against all organism (gram positive and gram negative). But unfortunately studies $[6,11]$ from other part of this country had not included this antibiotic in drug sensitivity test. They had found gram negative organisms most commonly in their study and quinolones was the most effective antibiotic against gram negative organisms. But we found quinolone to be less effective against gram negative organism. Ofloxacin was resistant in $26.67 \%$ and levofloxacin was resistant to $33.33 \%$ of patients having gram negative organisms. This may be because of very frequent use of quinolones in this area. Even though quinolones are effective, it should not be used frequently in our country where prevalence of tuberculosis is high.

\section{Conclusion}

Streptococcus pneumoniae is still the most common pathogen in patients with AECOPD of this area and piperacilline+tazobactum is the most effective antibiotic against all organisms. So, piperacilline+tazobactus should be the first choice empirical antibiotics for AECOPD patients in this area. Quinolones should be used cautiously in area where prevalence of tuberculosis is high.

\section{Limitations}

Spontaneously expectorated sputum was used for microbiological sampling. The accuracy could be increased by taking sample bronchoscopically.

\section{Recommendations}

Large study is which include of all severity of the stable COPD patients as well as AECOPD patients with comparison of sputum (including quality) and bronchocopic sample cultures is required.

\section{References}

1. Global initiative for chronic obstructive lung disease (GOLD) (2011) Global strategy for the diagnosis, management, and prevention of COPD.

2. Jindal SK (2006) Emergence of chronic obstructive pulmonary disease as an epidemic in India. Indian J Med Res 124: 619-630.

3. Rutten-van Mölken MP, Postma MJ, Joore MA, Van Genugten ML, Leidl R, et al. (1999) Current and future medical costs of asthma and chronic obstructive pulmonary disease in The Netherlands. Respir Med 93: 779-787.

4. Mannino DM (2002) COPD: epidemiology, prevalence, morbidity and mortality and disease heterogeneity. Chest 121: 121S-126S.

5. Rennard SI, Farmer SG (2004) Exacerbations and progression of disease in asthma and chronic obstructive pulmonary disease. Proc Am Thorac Soc 1 : 88-92.

6. Chawla K, Mukhopadhay C, Majumdar M, Bairy I (2008) Bacteriological profile and their antibiogram from cases of acute exacerbations of chronic obstructive pulmonary disease: A hospital based study. Journal of Clinical and Diagnostic Research 2: 612-616.

7. Adams SG, Melo J, Luther MS, Anzueto A (2000) Antibiotics are associated with lower relapse rates in outpatients with acute exacerbations of COPD. Chest 117: 1345-52.

8. Shahnawaz A, Saleem SM, Bhat MA, Bhat G, Dhobi GN (2003) Bacteriological profile in acute exacerbation of chronic obstructive pulmonary disease (COPD). JK Practitioner 10: 185-187. 
Citation: Patel AK, Luhadia AS, Luhadia SK (2015) Sputum Bacteriology and Antibiotic Sensitivity Pattern of Patients Having Acute Exacerbation of COPD in India - A Preliminary Study. J Pulm Respir Med 5: 238. doi:10.4172/2161-105X.1000238

9. Brusse-Keizer MG, Grotenhuis AJ, Kerstjens HA, Telgen MC, van der Palen J et al. (2009) Relation of sputum colour to bacterial load in acute exacerbations of COPD. Respir Med 103: 601-606.

10. Ko FW, Ng TK, Li TS, Fok JP, Chan MC, et al. (2005) Sputum bacteriology in patients with acute exacerbations of COPD in Hong Kong. Respir Med 99: 454-460.

11. Madhavi S, Ramarao MV, Janardhanrao R (2012) Bacterial etiology of acute exacerbations of chronic obstructive pulmonary disease. Journal of Microbiology and Biotechnology Research 2: 440-44.
12. Groenewegen KH, Wouters EF (2003) Bacterial infections in patients requiring admission for an acute exacerbation of COPD; a 1-year prospective study. Respir Med 97: 770-777.

13. Eller J, Ede A, Schaberg T, Niederman MS, Mauch H, et al. (1998) Infective exacerbations of chronic bronchitis: relation between bacteriologic etiology and lung function. Chest 113: 1542-1548.

14. Miravitlles M, Espinosa C, Fernández-Laso E, Martos JA, Maldonado JA et al. (1999) Relationship between bacterial flora in sputum and functional impairment in patients with acute exacerbations of COPD. Study Group of Bacterial Infection in COPD. Chest 116: 40-46. 